\title{
Review of interrelationnursingdiagnosis Sedentary
}

\author{
Milagrosa Olmedo Alguacil ${ }^{1}$, Alejandro Ramírez Aracena ${ }^{2}$, Pedro Martí Siles ${ }^{3}$, \\ Juan Carlos López Fontalba ${ }^{4}, \mathrm{M}^{\mathrm{a}}$ Mar Alfaya Góngora ${ }^{5}$, \\ José Manuel Alguacil García . \\ 1, 2, 3, 4.Departamento de Enfermería, Facultad de Ciencias de la Salud de Ceuta, Universidad de Granada, \\ Spain. \\ 5. Departamento de Enfermería, Facultad de Enfermería de Melilla, Universidad de Granada, Spain. \\ 6. Departamento de Educación. Facultad de Humanidades de Ceuta, Universidad de Granada, Spain
}

\begin{abstract}
In the new edition of NursingDiagnoses 2012-2014 from NANDA International, Sedentary Diagnostic is shown under a new LEVEL/DOMINIUM, from level 4:Activity-Rest to level 1: Health promotion. This fact may imply some modifications with respect to the interrelations proposed for the NOCs (interrelations, 2006). The aim of this study is that of obtaining new results that might cover psychosocial aspects of Sedentary Diagnostic. Material and methods; 25 nurses were chosen, to whom a questionnaire was sent in which 78 answers were specified, with their definition and a scale going from 1 to 5, where 1 means "Not representative at all", 2 "Some importance", 3 "relatively important", 4 "Quite important and 5 "Very important". The value of the answers given to each of them is that of 0, 0.25, 0.5, 0.75, 1. Results according to Fehring technique (1987). Among all of them, three of the results were considered to obtain high punctuations: Motivation $(0,88)$, Quality of life $(0,88)$ and Health Condition $(0,88)$. As a conclusion, the results obtained seem to propose changes in the interrelations within NOCs in sedentary diagnosed. A new set of NOCs ought to be included in order to evaluate the psychosocial aspects of a person.
\end{abstract}

Keywords: NANDA, NOC, Nursing diagnostic Sedentary.

\section{Introduction}

The MEDICAL diagnostic "Sedentary" (code 00168) is defined by Guiaro-Goris as "Human answer in response to a habit which main characteristic is a low physical activity..." located within level 4 "Activity/rest", from 2004 to 2010. level 4 "Activity/Rest" is defined as "Production, preservation, the use or the equilibrium of energetic resources" although this definition lacks some important information since it does not consider emotional, motivational or social aspects as well as health perception or well being awareness. This diagnostic has a great impact on developed societies, where there is a tendency towards a low physical activity and a high tendency towards spending time on home chores, studying and work. Eventually, it is also a high risk in terms of cardiovascular, respiratory and metabolic problems.

In the edition of NANDA -I 2012-2014, this diagnostic has changed its place, moving from level 1 "Health Promotion", which is defined as "self awareness of personal well being or functional normality and strategies used to control and develop personal well beingand normal body functions", and since we have an overall view of the patient with low physical activity, we are able to evaluate the problem not only as a physical state, but also as a bio-psychosocial being who needs support and courage so as to abandon unhealthy habits, thusevaluating behavior changes, interests and mental states, being able to fulfill from the overall view the study of this diagnostic.

Formerly, the evaluation of a sedentary patient was only fulfilled from a physical point of view, attending level 4. Interrelations NOC for this diagnostic showed: Physical condition (2004), Tolerance to physical activity (0005) and Stamina (0001). These had very few indicators related to patient motivation or their personal well being, which are considered essential in order to obtain a total adaptation with a low incidence in this new healthy life style, and to be adjusted to the new diagnostic and its change of level.

After this change, sedentary lifestyle has been proposed to be tested with new interrelations among new aspects. This is supported by the literature which clearly establishes a relation between a greater physical activity with a lower anxiety level or improving the quality of life among other factors, to complete the interrelations of the new concept of sedentary proposed.

NOC "Anxiety Level" (code 001211) is defined as "Suffering apprehension, tension or anxiety emerged from a non identifiable source". Different studies propose a correlation of a greater physical activity with a lower degree of anxiety levels, such as those by Akandere, M. and Tekin, A. (2005) and Azurra, J. A. (2007). The importance of this NOC relies on the fact that it is a great short term indicator of access to treatment since the patient is able to control anxiety, feeling the improvement in their mental state in a few weeks, and thus keeping an optimum level, being therefore more adaptable to stress. 
NOC defines "Personal well being" (code 002002) as "Having a positive perception of a personal health state". The study by Medina J. et al. (2012), shows that sedentary people have a lower personal satisfaction than those with a little physical activity, or at least rehabilitation therapy. That is the reason why it is important to consider the physical activity of the patient, even if it only consists on rehabilitation therapy.

NOC "Attitude in gaining health" (code 001603) is defined as "Personal actions to improve well being, recovering and positive rehabilitation". Bandura's theory of self-sufficiency confirms that people who show a greater interest towards changing their attitude have better results than those not showing any interest on it.

NOC "Motivation" (code 001209) is defined as "Inner feeling that moves a person towards positive actions". According to Ugalde et al (2009), the main reason for patients not to do any physical activity is the lack of motivation, being $77 \%$ of the reasons given by the patients themselves. That is the reason why in long term conditions, looking for strategies to motivate patients may seem fundamental in order to attain the main aims.

Last NOC proposed is "Quality of life" (code 002000) defined as "Capacity to have a positive perception of the quality of life" which correlates life habits with little physical activity with a low quality of life. This is shown in the study by García Pérez R. (2007), which shows, with a great sample, that sedentary people have a lower quality of life.

The importance of evaluating the psychological factor is based on the idea that patients should feel comfortable in order to get involved into treatment, satisfied and motivated with the activities performed as well as being able to obtain answers to the doubts about the activity they develop. Obtaining satisfaction with physical aims such as for example "control over arterial pressure", "regulation of heart rate" etc, is not enough to obtain success so as to eliminate the sedentary diagnosis, since once levels reach their maximum peak, the patient will lose interest, and that is the reason why diagnosis and evaluation should continue with the diagnosis and its evaluation on psychological factors such as lack of interest in the patient or not feeling well with the activities they develop, even though there may be improvement with respect to the physical evaluation.

\subsection{Aims}

1. Validating NOCs covering psychosocial aspects in a person with sedentary diagnosed

\section{Material And Method}

A study was made in order to validate contents. In order to do so, three steps were taken.

First step consisted on research of bibliographic references, working with the Classification of Nursery Results (NOC) 2009 in Spanish as a first reference. levels were researched so that they could correlate with the new level Sedentary Diagnosed. Due to the change of level of the diagnosis in the last NANDA edition, it was decided to work with two different levels, level III: Psychosocial health and level V: Perceived health, since they were the ones which adjusted themselves better with the new way to work with sedentary diagnosed. A table was made where the 78 answers were written, including all the categories of these two levels. A definition of each of them was also included together with five different categories from 1 to 5 , where 1 means "Not representative at all", 2 "Some importance", 3 "relatively important", 4 "Quite important and 5 "Very important". The value of the answers given to each of them is that of $0,0.25,0.5,0.75,1$.

After this first step, the Fehring technique was used, through which a personalized experts panel with 25 nurses was developed, from December 2012 to February 2013; 4 of the nurses were experts according to Fehring, but the rest had over 20 years experience in primary attention and day care nursery. In order to validate this proposal, a compilation of the suggested NOCs were sent to the different nurses, so they could punctuate them.

\section{Results}

Once the results were compiled, those with a higher punctuation were shown as seen in table 1.The result obtained from the survey was calculated over a descriptive statistics treatment with the punctuations in relation to the number of nurses involved.

\begin{tabular}{|ll|}
\hline NOC & Punctuation \\
\hline \hline Personal well-being & 0.66 \\
Healthyhabitslifestyle & 0.59 \\
Anxietylevel & 0.79 \\
Physicalshape & $\mathbf{0 . 8 0}$ \\
Quality of life & $\mathbf{0 . 8 8}$ \\
Stamina & 0.55 \\
Physicalactivitytolerance & 0.70 \\
Motivation & $\mathbf{0 . 8 8}$ \\
\hline
\end{tabular}

TABLE 1: Higherpunctuations for the results, which should be included in the Sedentary, diagnosed correlations 


\section{Conclusions}

This study is a pilot test. It has been proved that a change of level in the diagnosis influences the interrelations with the NOCs. Evidence shown may not be conclusive enough, since it would be necessary a longer period of time to work with expert nurses and search similar studies to compare and observe repetiton of the incidences found by the experts in our study.

There are studies which correlate NOCs proposed with sedentarysm diagnosed, but not from a nursery point of view. It was already well known the need to evaluate sedentarism as a biopsichosocialproblem, when Guirao-Goris stated: “Also, from a psychological point of view physical activity releases anxiety, depression..."

The third step of the study was focused on the results obtained. According to Fehring, results are considered as "high" when an average punctuation of 0.8 or higher is obtained. A result between 0.79 and 0.6 is considered "intermediate" and needs to undergo a new revisión. Results under 0.6 are considered "low" and will not be taken into account. That is the reason why it was decided to work with the results shown in table 1 , since the rest of the results obtained a punctuation under 0.40 , so they were not taken into account as NOCs interrelating directly with sedentarism diagnosed.

From the results with higher punctuations, only three out of five could be adjusted to the evaluation of the diagnosis in the new level: Physical shape (0.80), Quality of life (0.88) and Motivation (0.88). Anxiety level could be accepted (0.79) since punctuation obtained is close to the basic requirements.

Personal wellness and health search behaviour will not be taken into account since punctuations fall into an average range.

\section{Referencies}

[1]. Guirao-Goris. "Validación del contenido diagnóstico de la etiqueta diagnóstica enfermera 'sedentarismo'” - Editorial ElsevierAvailable at: http://www.elsevier.es/es/revistas/enfermeria-clinica-35/validacion-contenido-diagnosticoetiquetadiagnostica-enfermera-sedentarismo-13018133-originales 2001?bd=1. Accessed 1/17/2013, 2013.

[2]. Nandainternacional,Nanda diagnósticos enfermeros 2009-2011 definiciones y clasificación. (Ediciones Elsevier. 2010)

[3]. Nanda internacional, Nanda diagnósticos enfermeros 2012-2014 definiciones y clasificación.(Ediciones Elsevier. 2012)

[4]. Nanda internacional, Interrelaciones Nanda, Nic y Noc.(Ediciones Elsevier. 2006)

[5]. Nandainternacional,Clasificación de Resultados de Enfermería NOC. (Ediciones Elsevier. 2009)

[6]. Fehring RJ. Methods to Validate Nursing Diagnoses Heart Lung 1987 -1101:http://epublications.marquette.edu/cgi/viewcontent.cgi?article=1026\&context=nursig_fac

[7]. HeinSeganfredo D, de Abreu Almeida M. Validación de contenido de resultados de enfermería según la Clasificación de los Resultados de Enfermería (NOC) para pacientes clínicos, quirúrgicos y críticos. jan.-feb. 2011;2013(jan.-feb. 2011):http://ead.eerp.usp.br/rlae/- http://www.scielo.br/pdf/rlae/v19n1/es 06. pdf 